19

\title{
Усиление фотолюминесценции и комбинационного рассеяния в гибридных тонкопленочных структурах $a$-С:H с наночастицами серебра
}

\author{
(C) E.A. Коншина ${ }^{1}$, Д.П. Щербинин ${ }^{1}$, M.M. Aboud ${ }^{1,2}$ \\ ${ }^{1}$ Университет ИТМО, \\ 197101 Санкт-Петербург, Россия \\ ${ }^{2}$ Mansoura University, \\ 35516 Mansoura, Egypt \\ e-mail: eakonshina@mail.ru
}

Поступила в редакцию 21.11.2019 г.

В окончательной редакции 29.11.2019 г.

Принята к публикации 02.12.2019 г.

\begin{abstract}
Изучены изменения в спектрах оптической плотности, фотолюминесценции (ФЛ) и КР гибридных тонкопленочных структур на основе $a$-С:Н и гранулированных серебряных пленок до и после отжига образцов при $200^{\circ} \mathrm{C}$. Гипсохромный сдвиг основного плазмонного пика, формирование двойных резонансных спектров и усиление интенсивности полос наблюдались после отжига образцов с гравиметрической толщиной пленки $\mathrm{Ag} 10 \mathrm{~nm}$. Показано влияние на плазмонное усиление спектров ФЛ и КР изменений как морфологии наноструктуры пленок $\mathrm{Ag}$, так и особенностей электронной структуры пленок $a-\mathrm{C}: \mathrm{H}$. У образцов на основе $a$-С:Н с оптической щелью $E_{g}=0.4 \mathrm{eV}$ наблюдалось более эффективное усиление ФЛ после отжига образцов. В то же время у образцов с $E_{g}=2.7 \mathrm{eV}$ интенсивность ФЛ практически не изменялась, оставаясь более высокой. Усиление резонансного КР имело избирательный характер. Оно было связано с рассеянием на полициклических ароматических группах, преобладающих в структуре пленки $a$-С:H с более узкой оптической щелью.
\end{abstract}

Ключевые слова: аморфный углерод, серебряные наночастицы, плазмонный резонанс, фотолюминесценция, комбинационное рассеяние.

DOI: $10.21883 /$ OS.2020.03.49070.314-19

\section{Введение}

Разработка новых гибридных структур на основе люминесцирующих материалов и плазмонных наночастиц является одним из активно развивающихся направлений фотоники. Связанное состояние экситона и плазмона может вызывать как расщепление Раби, так и способствовать усилению люминесценции [1]. С другой стороны, сочетание слабо люминесцирующих объектов с плазмонными наночастицами может приводить к гигантскому комбинационному рассеянию [2].

В последнее время возник интерес к композитам на основе аморфного углерода и плазмонных наночастиц (НЧ). $\mathrm{Au}$ и Ag НЧ встраивались в аморфную углеродную матрицу [3-7], использовались в качестве промежуточного слоя с углеродными пленками различной толщины [8] и осаждались на их поверхность [9-11]. Исследования локализованного поверхностного плазмонного резонанса (LSPR - Localized surface plasmon resonance) наночастиц благородных металлов $\mathrm{Au}$ и $\mathrm{Ag}$ в гибридных структурах с аморфным углеродом как диэлектрической средой актуально для практических применений как в электронных, так и в фотонных устройствах. Такие гибридные структуры использовались в качестве электродов в суперконденсаторах [12], антибактериальных материалов [13], в сенсорах [14] и УФ фотоприемниках [15]. Была показана перспективность поверхностного плазмонного усиления фотолюминесценции (ФЛ) пленки аморфного гидрогенизированного углерода $(a-\mathrm{C}: \mathrm{H})$ с подслоем серебра для светоизлучающих устройств [8].

Оптические свойства $a-\mathrm{C}: Н$ определяются относительным содержанием в их структуре атомов углерода в $s p^{2}$ - и $s p^{3}$-гибридизации электронных оболочек, а также связанного водорода. Показатель преломления, поглощение и ширину оптической щели можно варьировать в широких пределах, изменяя условия получения $a-\mathrm{C}: \mathrm{H}$ химическим осаждением паров углеводородов в плазме тлеющего разряда [16]. Это делает такие пленки перспективным материалом для разработки гибридных структур с металлическими наночастицами. Была показана возможность вариации положения и интенсивности пика плазмонного резонанса наночастиц $\mathrm{Au}$ и $\mathrm{Ag}$ в гибридных структурах с $a$-С:H $[9,10]$. Экспериментально продемонстрировано многократное плазмонное усиление люминесценции пленок $a$-С:Н при осаждении на их поверхность Ag НЧ [11] и получены двойные резонансные спектры в таких структурах [17].

В этой работе основное внимание уделяется особенностям плазмонного усиления ФЛ и КР пленок $a$-С:Н в 
гибридных структурах с гранулированными серебряными пленками. Для этого проводится сравнение спектров оптической плотности, ФЛ и КР образцов и исследуется влияние на них морфологии наноструктуры пленок $\mathrm{Ag}$ и оптической ширины пленок $a$-С:Н до и после отжига образцов гибридных структур.

\section{Материалы и методы эксперимента}

Пленки $a$-С:Н получали химическим осаждением паров толуола в плазме тлеющего разряда на постоянном токе, поддержимаемой магнетронной плазмой локализованной вблизи анода [12]. Пленки осаждались на кварцевые подложки при комнатной температуре. Вариация их оптических свойств осуществлялась путем изменения мощности тлеющего разряда и давления в вакуумной камере. Пленки $a$-С:Н осаждались при мощности тлеющего разряда 8 и $1.6 \mathrm{~W}$ и давлении в вакуумной камере $4 \cdot 10^{-4}$ и $2 \cdot 10^{-4}$ Torr соответственно. Толщина пленок $a$-С:Н составляла $\sim 50 \mathrm{~nm}$.

Для контроля изменения оптических свойств $a-\mathrm{C}: \mathrm{H}$ пленок использовались спектры оптической плотности в интервале длин волн $200-1000 \mathrm{~nm}$. $E_{g}$ прозрачной и поглощающей в видимой области спектра пленок $a$-С:H оценивалась с помощью уравнения Тауца [13] и составила соответственно 2.7 и $0.4 \mathrm{eV}$.

Гранулированные серебрянные пленки получались термическим испарением в вакуумной камере PVD 75 (Kurt J. Lesker Company) при давлении $10^{-7}$ Torr и комнатной температуре и осаждались на пленки $a$-C:H. Исследования проводились с 4 образцами: N4, W4, N10 и W10. Первая буква обозначает ширину оптической щели пленки $a$-C:H: N (narrow) $E_{g}=0.4 \mathrm{eV}$ и W (wide) $E_{g}=2.7 \mathrm{eV}$. Цифра обозначает гравиметрическую толщину гранулированной пленки Ag: 4 и $10 \mathrm{~nm}$.

Спектры оптической плотности измерялись спектрофотометром СФ-56 (ЛОМО, Россия). Морфология поверхности пленок $\mathrm{Ag}$ изучалась с помощью атомносилового микроскопа (ACM) Solver PRO-M (NT-MDT, Россия) в полуконтактном режиме зондом HA_NC c радиусом кривизны менее $10 \mathrm{~nm}$. Спектры комбинационного рассеяния были получены с помощью микроспектрометра „In Via“ (Renishaw, Великобритания), оборудованного многоканальным детектором. Источником возбуждения на длине волны $514 \mathrm{~nm}$ являлся $\mathrm{Ar}^{+}$ионный лазер. Время накопления составляло $60 \mathrm{~s}$, спектральное разрешение $2 \mathrm{~cm}^{-1}$. Объектив Leica с увеличением $50 \times$ и числовой апертурой 0.75 использовался для освещения образца, и рассеянный свет собирался тем же объективом. Спектры фотолюминесценции измеряли с помощью конфокального сканирующего микроскопа LSM 710 на основе штатива Axio Imager Z1 (Carl Zeiss, Германия), используя для возбуждения излучение диодного лазера на длине волны $405 \mathrm{~nm}$.

\section{Результаты и обсуждения}

\section{Наноструктура гранулированных серебряных пленок}

2D изображения морфологии наноструктуры гранулированных серебряных пленок на поверхности $a$-C:H до и после отжига образцов, полученные с помощью $\mathrm{ACM}$, показаны на рис. 1. Морфология наноструктуры пленки $\mathrm{Ag}$ толщиной $4 \mathrm{~nm}$ у образцов N4 и W4 представляет собой плотно упакованные наночастицы $\mathrm{Ag}$ полусферической формы как до (рис. $1, a$ ), так и после отжига (рис. $1, c)$. Поверхность серебряной пленки толщиной $10 \mathrm{~nm}$ у образцов N10 и W10 состоит из плоских агрегатов НЧ (рис. $1, b)$, которые после отжига образуют изолированные НЧ полусферической формы (рис. $1, d$ ). При этом существенного влияния свойств пленок $a$-С:H на наноструктуру гранулированных серебряных пленок не наблюдалось.

\section{Локализованный поверхностный плазмонный резонанс в наночастицах $\mathrm{Ag}$ на поверхности $a-\mathrm{C}: \mathrm{H}$}

Спектры оптической плотности исследуемых образцов N4 и W4, а также N10 и W10 до и после их отжига при $200^{\circ} \mathrm{C}$ в течение $10 \mathrm{~min}$ показаны на рис. $2, a$ и $b$. Основной пик LSPR в спектрах оптической плотности этих структур связан с возбуждением дипольной моды. Положение полосы плазмонного резонанса сдвигается в коротковолновую область спектра. Интенсивность этой полосы в образцах с прозрачной $a-\mathrm{C}: Н$ пленкой больше, чем в образцах с поглощающей пленкой. Слабые пики в коротковолновой области спектра наблюдаются в спектрах образцов N10 и W10.

Отжиг исследуемых гибридных структур привел к дальнейшему смещению основного плазмонного пика в коротковолновую область в спектрах всех образцов (рис. 2, $a$ и $b$ ). При этом в спектрах образцов N10 и $\mathrm{W} 10$ с более толстой серебряной пленкой на рис. 2,b наблюдаются две узкие интенсивные полосы. Природа коротковолновой полосы может быть связана как с усилением интенсивности квадрупольной моды, так и с расщеплением Раби в результате сильного экситонплазмонного взаимодействия в исследуемых гибридных структурах [17]. Это возможно благодаря возбуждению электрон-дырочных пар в $a$-С:H широком интервале длин волн.

Как известно, положение плазмонного пика может зависеть от размера и формы НЧ и показателя преломления окружающей их диэлектрической среды $[18,19]$. Эллипсометрические исследования пленки $a-\mathrm{C}: \mathrm{H}$, полученной из паров толуола, показали, что для нее характерна нормальная дисперсия показателя преломления и коэффициента экстинкции в видимой области спектра, которая не изменялась в результате отжига 

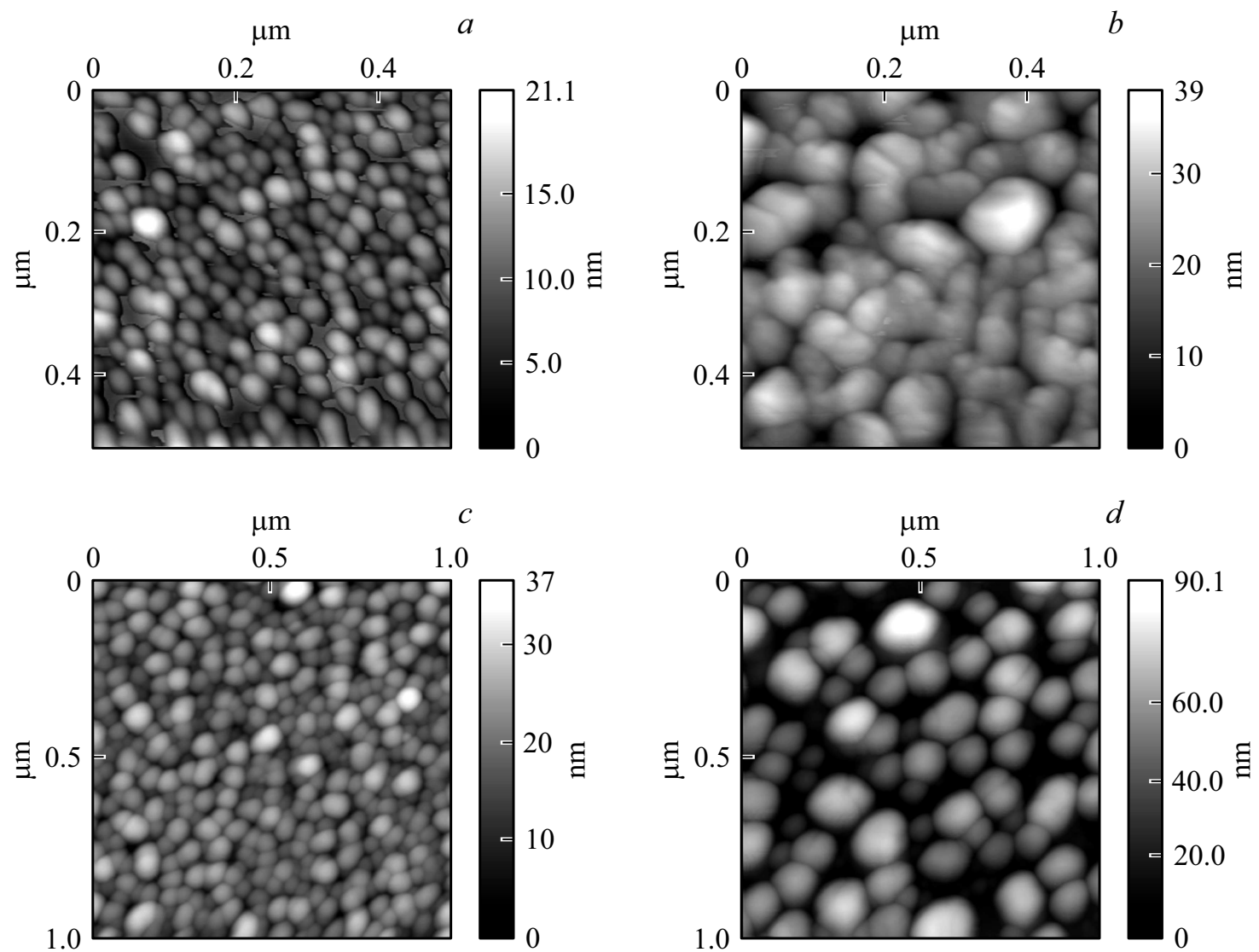

Рис. 1. 2D изображения в ACM наноструктуры гранулированных серебряных пленок с гравиметрической толщиной $4 \mathrm{~nm}(a, c)$ и $10 \mathrm{~nm}(b, d)$, осажденных на поверхность пленок $a$-С:Н до и после отжига образцов $10 \mathrm{~min}$ при $200^{\circ} \mathrm{C}$.
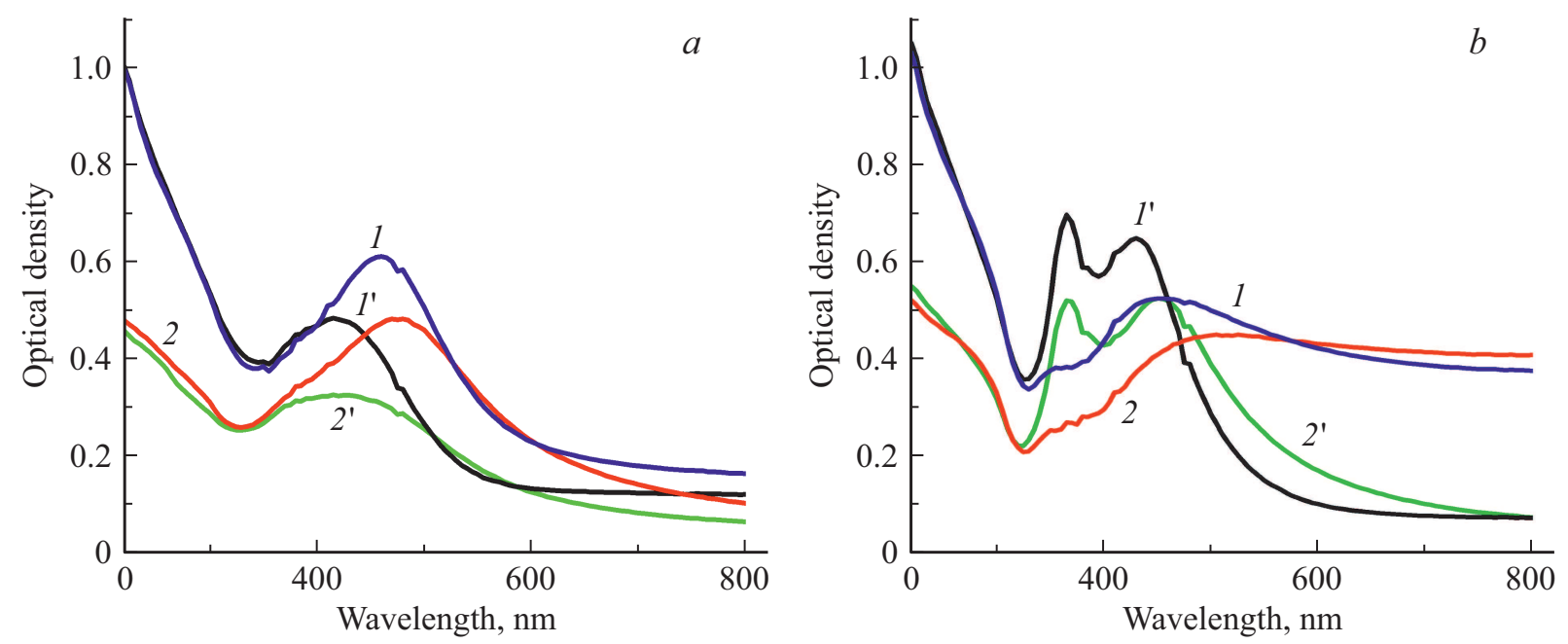

Рис. 2. Спектры оптической плотности гранулированных серебряных пленок, осажденных на поверхность пленок $a$-С:Н с $E_{g}=2.7 \mathrm{eV}(1)$ и $E_{g}=0.4 \mathrm{eV}(2)$ до и после их отжига $\left(1^{\prime}, 2^{\prime}\right) 10 \mathrm{~min}$ при $200^{\circ} \mathrm{C} . a-$ для W4 и N4 образцов с гравиметрической толщиной пленки серебра $4 \mathrm{~nm} ; b$ - для образцов W10 и N10 с гравиметрической толщиной пленки серебра $10 \mathrm{~nm}$.

при $300^{\circ} \mathrm{C}$ [20]. Изменение показателя преломления у таких пленок от 1.8 до 1.6 при вариации условий осаждения [21] коррелирует с увеличением ширины их оптической щели [16]. Таким образом, смещение пика в спектрах образцов W4 и W10 по сравне- нию со спектрами образцов N4 и N10 можно объяснить уменьшением показателя преломления пленок $a$-С:Н и увеличением их $E_{g}$. В то время как усиление интенсивности и образование двойных плазмонных спектров может быть связано с изменением на- 

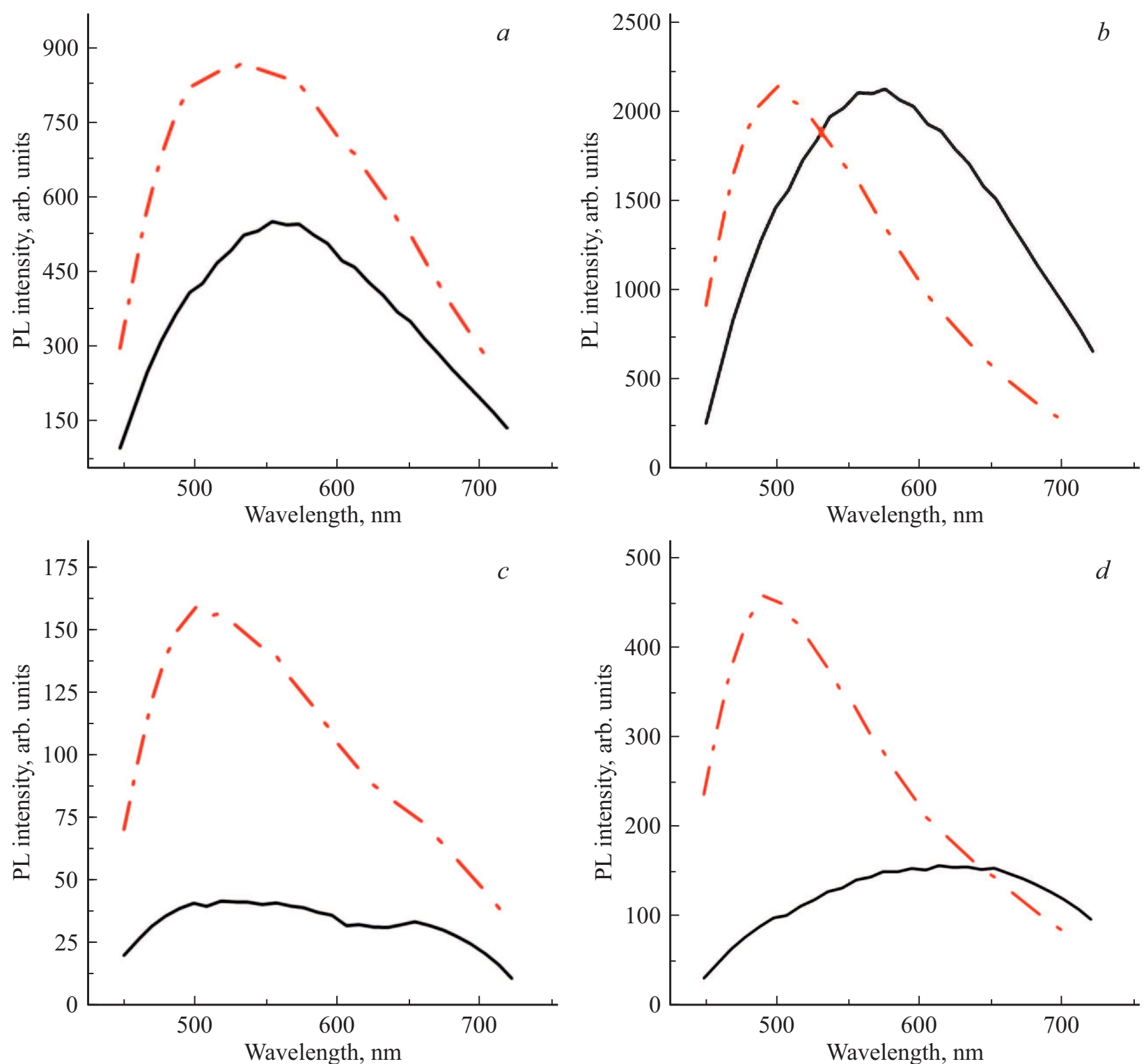

Рис. 3. Спектры фотолюминесценции гибридных структур на основе тонких пленок $a$-С:Н, покрытых гранулированной серебряной пленкой толщиной 4 и $10 \mathrm{~nm}$, до (сплошные линии) и после (штрихпунктирные линии) отжига образцов при $200^{\circ} \mathrm{C} 10 \mathrm{~min} . a$ и $b-$ спектры образцов W4 и W10; $c$ и $d-$ спектры образцов N4 и N10. Длина волны возбуждения спектров $405 \mathrm{~nm}$.

ноструктуры пленки $\mathrm{Ag}$ толщиной $10 \mathrm{~nm}$ после отжига образцов.

\section{Усиление фотолюминесценции пленок a-С:Н возбуждением плазмонов в наночастицах $\mathrm{Ag}$ на их поверхности}

Как известно, спектры фотолюминесценции $a$-С:H имеют широкую спектральную полосу в видимой области [22]. У образцов исследуемых гибридных структур ФЛ наблюдалась в интервале от 450 до $750 \mathrm{~nm}$, как можно видеть на рис. 3. Первоначальная интенсивность ФЛ гибридных структур была больше у образцов W4 и W10 на основе прозрачной пленки $a-\mathrm{C}: \mathrm{H}$ с широкой оптической щелью (рис. $3, a$ ), чем у образцов N4 и N10 на основе поглощающей $a$-С:Н с узкой щелью (рис. $3, c$ ).

После отжига образцов гибридных структур интенсивность ФЛ в спектре образца W4 увеличилась в 1.5 раза (рис. 3,a). Однако она практически не изменилась у образца W10 (рис. $3, b$ ). Более существенные изменения ФЛ наблюдаются в спектрах образцов $\mathrm{N} 4$ (рис. 3,c) и N10 (рис. $3, d$ ) на основе $a-\mathrm{C}: \mathrm{H}$ с узкой оптической щелью и слабой люминесценцией. У образца $\mathrm{N} 4$ интенсивность ФЛ увеличилась в 3.8 раза, а у образца N10 в 2.9 раза. Отжиг образцов привел к асимметрии спектров ФЛ у всех исследованных образцов в результате смещения максимумов в коротковолновую область. Для 
Параметры полос $D$ и $G$ в КР-спектрах пленок $a$-C:H с $E_{g}=2.7 \mathrm{eV}$ и $E_{g}=0.4 \mathrm{eV}$ до и после отжига образцов W4 и N4

\begin{tabular}{|c|c|c|c|c|c|c|}
\hline \multirow{2}{*}{$\begin{array}{c}\text { Образцы } \\
\text { Параметры } \\
\text { полос }\end{array}$} & \multicolumn{3}{|c|}{ N4 } & \multicolumn{3}{|c|}{ W4 } \\
\hline & $\begin{array}{c}\text { Положение } \\
\text { максимума, } \mathrm{cm}^{-1}\end{array}$ & $\begin{array}{l}\text { FWHM, } \\
\mathrm{cm}^{-1}\end{array}$ & $\begin{array}{c}\text { Интегральная } \\
\text { интенсивность, } \mathrm{cm}^{-1}\end{array}$ & $\begin{array}{c}\text { Положение } \\
\text { максимума, } \mathrm{cm}^{-1}\end{array}$ & $\begin{array}{l}\text { FWHM, } \\
\mathrm{cm}^{-1}\end{array}$ & $\begin{array}{c}\text { Интегральная } \\
\text { интенсивность, } \mathrm{cm}^{-1}\end{array}$ \\
\hline \multicolumn{7}{|c|}{ Исходные } \\
\hline $\begin{array}{c}D \\
G \\
I_{D / G}\end{array}$ & $\begin{array}{l}1387 \\
1566\end{array}$ & $\begin{array}{l}303 \\
153\end{array}$ & $\begin{array}{c}10 \cdot 10^{4} \\
16 \cdot 10^{4} \\
0.625\end{array}$ & $\begin{array}{l}1352 \\
1545\end{array}$ & $\begin{array}{l}221 \\
166\end{array}$ & $\begin{array}{c}19 \cdot 10^{4} \\
44 \cdot 10^{4} \\
0.43\end{array}$ \\
\hline \multicolumn{7}{|c|}{ После отжига } \\
\hline $\begin{array}{c}D \\
G \\
I_{D / G}\end{array}$ & $\begin{array}{l}1391 \\
1581\end{array}$ & $\begin{array}{l}317 \\
122\end{array}$ & $\begin{array}{c}19.5 \cdot 10^{5} \\
10 \cdot 10^{5} \\
2\end{array}$ & $\begin{array}{l}1367 \\
1556\end{array}$ & $\begin{array}{l}229 \\
157\end{array}$ & $\begin{array}{c}74 \cdot 10^{4} \\
13 \cdot 10^{5} \\
0.57\end{array}$ \\
\hline
\end{tabular}

образцов W4 и $\mathrm{N} 4$ он составил 36 и $41 \mathrm{~nm}$, а для образцов W10 и N10 на 77 и $150 \mathrm{~nm}$ соответственно. Положение максимума интенсивности ФЛ в отожженных образцах было около $500 \mathrm{~nm}$, что указывает на более вероятное плазмонное усиление ФЛ на этой длине волны. Стоит заметить, что интенсивность ФЛ в гибридных структурах с более толстыми серебряными пленками существенно была выше как до, так и после отжига образцов.

Излучающими центрами в $a$-С:Н являются электронно-дырочные пары, локализованные в $\pi$-связанных кластерах, состоящих из ароматических колец и алифатических цепей с сопряженными кратными связями. Эти кластеры беспорядочно распределены в $s p^{3}$ связанной матрице. Увеличение размеров $\pi$-кластеров приводит к увеличению плотности $\pi$ - и $\pi^{*}$-состояний в внутри $\sigma-\sigma^{*}$ оптической щели $a-\mathrm{C}: \mathrm{H}$. Чем меньше размер $\pi$-кластера, тем выше энергия $\pi-\pi^{*}$-перехода [23]. Ширина оптической щели пленок $a$-С:Н определяется наименьшей энергией $\pi-\pi^{*}$ перехода. Формирование непрерывных спектров ФЛ пленок $a$-С:Н происходит в результате перекрытия полос поглощения отдельных $\pi$ кластеров с разными энергиями $\pi-\pi^{*}$ переходов.

В структуре $a$-С:Н с узкой оптической щелью размер $\pi$-кластеров больше, чем в пленках с более широкой оптической щелью. Кроме того, вероятность появления дефектных состояний внутри оптической щели из-за уменьшения содержания связанного водорода и образования в результате этого оборванных связей в них больше. Для этих пленок характерна делокализация $\pi$ электронов, что повышает вероятность безызлучательной рекомбинации электрон-дырочных пар. В то время как в прозрачной пленке с широкой оптической щелью из-за малых размеров кластеров и локализации в них $\pi$ электронов более вероятна излучательная рекомбинация электрон-дырочных пар.

Таким образом, на усиление интенсивности ФЛ $a$-С:H в тонкопленочных структурах с НЧ $\mathrm{Ag}$ могут влиять два основных фактора. Первый - это наноструктура гранулированной серебряной пленки на поверхности $a$-С:Н.
Размер наночастиц Ag определяет глубину проникновения затухающей волны возбужденного в них плазмона. При этом усиление люминесценции в подобных структуpax может происходить как за счет увеличения сечения поглощения, так и за счет эффекта Парселла. Вторым фактором является электронная структура $a-\mathrm{C}: \mathrm{H}$, зависящая от размера $\pi$-кластеров и локализации в них $\pi$-электронов. Об этом свидетельствует неодинаковая интенсивность ФЛ пленок $a$-С:Н с разной шириной оптической щели, а также ее изменения после отжига образцов гибридных структур с одинаковой толщиной серебряных пленок.

Из-за разной ориентации $\pi$-кластеров в структуре $a$-С:Н пленки и энергий $\pi-\pi^{*}$-переходов возможно избирательное взаимодействие экситонов, возбуждаемых в них, с плазмонами, возбуждаемыми в НЧ $\mathrm{Ag}$ на их поверхности. Связывание экситонов и плазмонов, возбужденных на одной длине волны, может также способствовать увеличению интенсивности ФЛ. Несмотря на уменьшение оптической плотности, после отжига образцов N4 и N10 с низкоэффективной исходной люминесценцией $a$-С:H (рис. $1, a, b)$ их ФЛ увеличилась значительно (рис. $3, c, d$ ).

\section{Усиление комбинационного рассеяния пленок $a$-С:Н при возбуждении плазмонов в наночастицах Ag на их поверхности}

Возбуждение комбинационного рассеяния в исследуемых образцах на длине волны $514 \mathrm{~nm}$ вызвало сильный фон люминесценции и засветку спектров у образцов W10 и N10. В КР-спектрах образцов гибридных структур W4 и N4 наблюдается широкая полоса в интервале $1100-1800 \mathrm{~cm}^{-1}$. Эта полоса характерна для спектров аморфного углерода, и ее условно можно разложить на две полосы гауссова типа, как показано на рис. 4. 

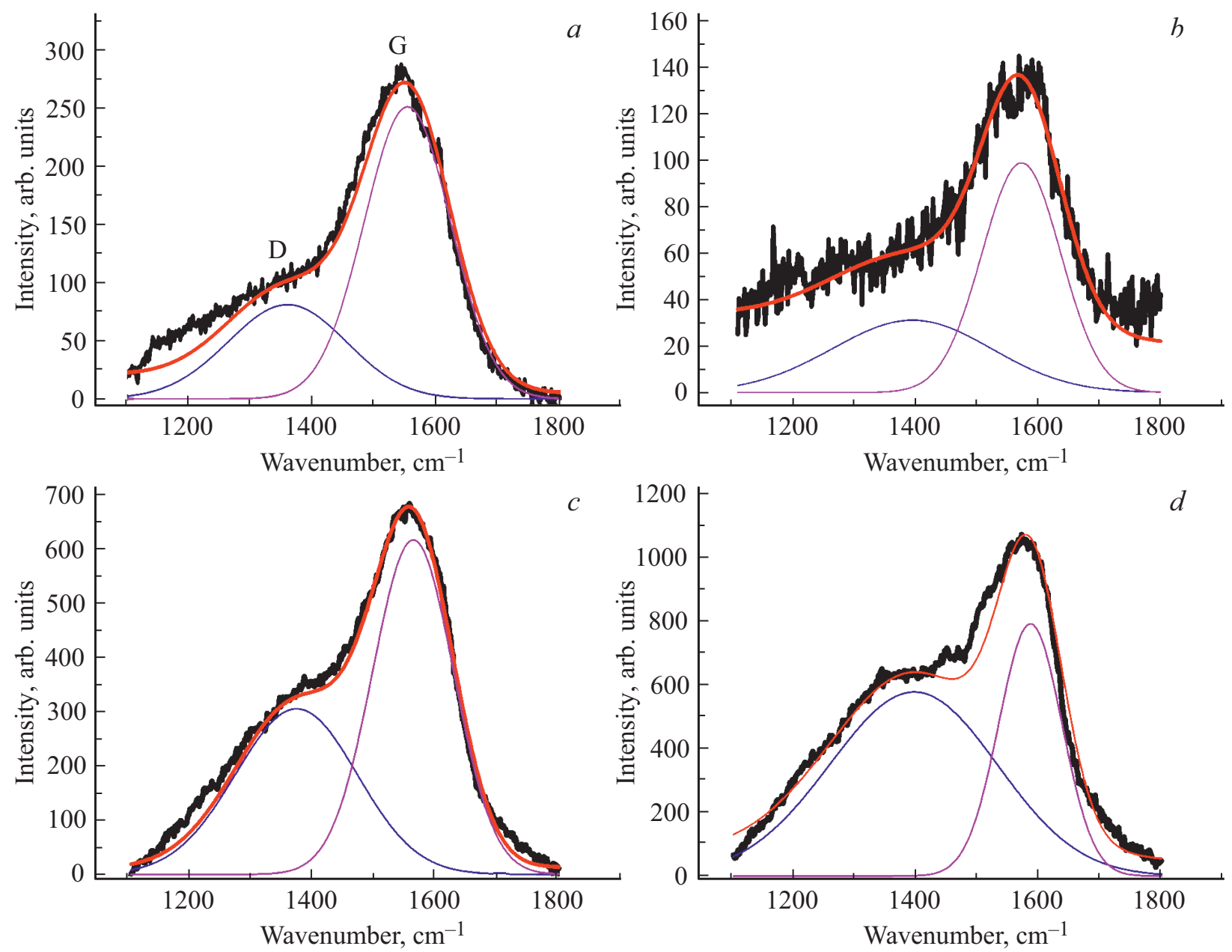

Рис. 4. КР спектры гибридных структур на основе $a$-С:Н пленок, покрытых гранулированной серебряной пленкой с гравиметрической толщиной $4 \mathrm{~nm}$, до и после отжига при $200^{\circ} \mathrm{C}$ в течение $10 \mathrm{~min}$ образцов $\mathrm{W} 4 \mathrm{c} E_{g}=2.7 \mathrm{eV}(a$ и $c$ ) и $\mathrm{N} 4$ c $E_{g}=0.4 \mathrm{eV}(b$ и $d)$. Длина волны возбуждения $514 \mathrm{~nm}$.

Низкочастотную полосу в спектрах аморфного углерода принято обозначать, как полоса $D$, а высокочастотную, как полоса $G$. В таблице приведены положения максимумов, ширина спектральной полосы (FWHM - full width at half maximum) и интегральная интенсивность полос $D$ и $G$, а также их отношение, полученное при разложении спектров КР образцов W4 и N4 до и после их отжига.

Положение максимумов полос у образца $\mathrm{N} 4$ смещено в область более высоких частот по сравнению с образцом W4. При этом отношение интегральных интенсивностей полос $D$ и $G$ больше у образца $\mathrm{N} 4$, как видно из таблицы. После отжига наблюдается батохромный сдвиг положения максимумов полос. Если у образца N4 отношение $I_{D / G}$ увеличилось в два раза, то у образца $\mathrm{W} 4$ только на $32 \%$ в результате изменения наноструктуры гранулированной пленки $\mathrm{Ag}$ после отжига гибридных структур.

В структуре пленок $a$-С:Н могут присутствовать два типа элементов, дающих вклад в их спектры КР. Длин- ные полиеновые цепи различной длины вносят основной вклад - в интенсивность полосы $G$, а полициклические ароматические группы с различным числом колец в интенсивность полосы $D$. Разброс электронных и колебательных параметров $a$-С:Н связан с различными размерами элементов структуры и неупорядоченным их расположением в $s p^{3}$-матрице. Резонансные условия возбуждения спектров КР приводят к избирательному усилению рассеяния на частотах тех элементов, для которых эти условия оптимальны [24].

Интегральная интенсивность полосы $D$ в спектре КР увеличилась примерно в 20 раз у образца N4 после отжига (таблица). Это связано с более эффективным резонансным рассеянием на полициклических группах в структуре $a-\mathrm{C}: \mathrm{H}$ в результате взаимодействия с плазмонами, возбуждаемыми в $\mathrm{Ag} \mathrm{HЧ}$ на их поверхности. В то же время у образца W4 наблюдается усиление интегральной интенсивности полосы $G$ в 3 раза (таблица). Учитывая тот факт, что структурные изменения в пленках $a$-C:Н маловероятны при температуре отжига 
$200^{\circ} \mathrm{C}$, можно предположить, что усиление интенсивности спектров КР связаны с возбуждением плазмонов в Ag НЧ.

Усиление комбинационного рассеяния зависит от наноструктуры серебряной пленки на поверхности пленок $a$-C:H, когда частота падающего излучения или рассеянного света перекрывает резонансную частоту электронов проводимости в ней. В этом случае коллективные колебания электронов, возбуждаемые в плазмонных наночастицах, генерируют электромагнитное поле, усиливающее поле падающего/рассеянного сигнала. Более значительное усиление КР наблюдается в образце N4 на основе пленки $a$-С:H с узкой оптической щелью (рис. 4,c). Это можно объяснить избирательным усилением резонансного комбинационного рассеяния на полициклических ароматических группах, преобладающих в структуре $a$-C:H пленки

\section{Заключение}

Изменения в спектрах оптической плотности, фотолюминесценции и КР гибридных тонкопленочных структур на основе $a$-С:Н и гранулированных серебряных пленок до и после отжига образцов при $200^{\circ} \mathrm{C}$ были исследованы. Формирование двух интенсивных узких резонансных плазмонных полос в спектрах наблюдалось в результате изменения наноструктуры пленок Ag толщиной $10 \mathrm{~nm}$ после отжига образцов. Это способствовало более эффективному плазмонному усилению спектров ФЛ слаболюминесцирующих образцов на основе $a-\mathrm{C}: \mathrm{H}$ c узкой оптической щелью. Причиной этого может быть образование связанных экситонов и плазмонов в таких структурах, возбуждаемых на одной длине волны. Плазмонное усиление резонансного КР имело избирательный характер. Интегральная интенсивность полосы $D$ увеличилась в $\sim 20$ раз в спектре КР образца с поглощающей пленкой $a-\mathrm{C}: \mathrm{H}$, покрытой пленкой $\mathrm{Ag}$ толщиной $4 \mathrm{~nm}$, после его отжига. Это свидетельствует об усилении комбинационного рассеяния на полициклических ароматических группах, преобладающих в структуре этой пленки $a$-С:Н. В образцах с пленкой $\mathrm{Ag}$ толщиной $10 \mathrm{~nm}$ наблюдался интенсивный фон люминесценции. Полученные результаты свидетельствуют о возможности направленного усиления интенсивности ФЛ и КР пленок $a$-С:Н в гибридных структурах с гранулированными серебряными пленками для создания фотонных устройств на их основе.

\section{Благодарности}

Авторы выражают благодарность И.А. Гладских, К.В. Богданову, П.С. Парфенову и В.В. Захарову за помощь в проведении измерений.

\section{Конфликт интересов}

Авторы заявляют, что у них нет конфликта интересов.

\section{Список литературы}

[1] Manuel A.P., Kirkey A., Mahdiaand N., Shankar K. // J. Mater. Chem. C. 2019. V. 7. P. 1821-1853. doi 10.1039/c8tc05054f

[2] Chu Y., Banaee M.G., Crozier K.B. // ACS Nano. 2010. V. 4. N 5. P. 2804-2810. doi $10.1021 / \mathrm{nn} 901826 \mathrm{q}$

[3] Paul R., Hussain S., Pal A.K. // Appl. Surf. Sci. 2009. V. 255. P. 8076-8083. doi 10.1016/j.apsusc.2009.05.018

[4] Talu S., Bramowicz M., Kulesza S., Solaymani S., Shafikhani A., Ghaderi A., Ahmadiraded M. // Ind. Eng. Chem. Res. 2015. V. 54. N 33. P. 8212-8218. doi 10.1021/acs.iecr.5b02449

[5] Ghosh B., Guzmán-Olivos F., Espinoza-González R. // J. Mater. Sci. 2017. V. 52. P. 218-228. doi 10.1007/s10853-016-0324-7

[6] Tamulevičius S., Meskinis S., Tamulevičius T., Rubahn H.-G. // Rep. Prog. Phys. 2018. V. 81. P. 024501 (31). doi 10.1088/1361-6633/aa966f

[7] Gholamali H., Shafiekhani A., Darabi E., Elahi S.M. // Results in Physics. 2018. V. 8. P. 336-340. doi 10.1016/j.rinp.2017.12.033

[8] Li Z., Li X., Ren Z., Gao Q., Zhang X., Han G. // Opt. Express. 2011. V. 19. N 19. P. 17935-17943. doi 10.1364/OE.19.017935

[9] Коншина Е.А., Щербинин Д.П., Abboud М.М., Гладских И.А. // Опт. и спектр. 2018. Т. 125. N 2. С. 274 276; Konshina E.A., Shcherbinin D.P., Abboud M.M., Gladskikh I.A. // Opt. Spectrosc. 2018. V. 125. N 2. P. 290 292. doi 10.1134/S0030400X18080155

[10] Konshina E.A., Shcherbinin D.P., Abboud M.M., Bogdanov K.V., Gladskikh I.A., Polischuk V.A. // App. Surf. Sci. 2019. V. 471. P. 652-657. doi 10.1016/j.apsusc.2018.12.078

[11] Konshina E.A., Abboud M.M., Shcherbinin D.P., Gladskikh I.A., Zakharov V.V., Parfenov P.S. // Diam. Relat. Mater. 2019. V. 98. P. 107470. doi 10.1016/j.diamond.2019.107470

[12] Dai E., Xu J., Qiu J., Liu S., Chen P., Liu Y. // Sci. Rep. 2017. V. 7. N 1. P. 12588. doi 10.1038/s41598-017-12733-5

[13] Anjana P.M., Bindhu M.R., Umadevi M., Rakhi R.B. // Appl. Surf. Sci. 2019. V. 479 P. 96-104. doi 10.1016/j.apsusc.2019.02.057

[14] Ghodselahi T., Neishaboorynejad T., Arsalani S. // Appl. Surf. Sci. 2015. V. 343. P. 194-201. doi 10.1016/j.apsusc.2015.01.219

[15] Chang X., Wang Y.F., Zhang X., Liu Z., Fu J., Zhao D., Wang H.X. // Appl. Surf. Sci. 2019. V. 464. P. 455-457. doi 10.1016/j.apsusc.2018.09.087

[16] Konshina E.A. // Crystalline and Non-crystalline Solids. InTech, 2016. P. 126. doi 10.5772/62704

[17] Shcherbinin D.P., Konshina E.A., Abboud M.M., Gladskikh I.A., Vartanyan T.A., Parfenov P.S. // J. Moden Opt. 2019. V. 66. P. 1889-1895. doi 10.1080/09500340.2019.1683241

[18] Noguez C. // Opt. Mater. 2005. V. 27. N 7. P. 1204-1211. doi 10.1016/j.optmat.2004.11.012 
[19] Noguez C. // J. Phys. Chem. C. 2007. V. 111. N 10. P. $3806-$ 3819. doi $10.1021 / \mathrm{jp} 066539 \mathrm{~m}$

[20] Толмачев В.А., Щербинин Д.П., Коншина Е.А. // Опт. и спектр. 2019. Т. 127. В. 5. Р. 846-850. Tolmachev V.A., Konshina E.A., Shcherbinin D.P. // Opt. Spectr. 2019. V. 127. N 5. P. 919-923. doi 10.21883/OS.2019.11.48526.197-19

[21] Tolmachev V.A., Konshina E.A. // Diam. Relat. Mater. 1996. V. 5. N 12. P. $1397-1401$. doi 10.1016/S0925-9635(96)00551-1

[22] Godet C., Heitz T., Dravillon B., Boureé J.E. // Int. J. Mod. Phys. B. 2000. V. 20. P. 1701-1717. doi 10.1142/S0217979200001795

[23] Füle M., Budai J., Tóth S., Veres M., Koós M. // J. Non-Cryst. Solids. 2006. V. 352. P. 1340-1343. doi 10.1016/j.jnoncrysol.2005.11.087

[24] Баранов А.В., Коншина Е.А. // Опт. и спектр. 1988. Т. 65. C. 856-860; Baranov A.V., Konshina E.A. // Opt. Spectrosc. 1988. V. 65. P. 506-509. 